\title{
Inhibition of proteasome deubiquitinase activity: a strategy to overcome resistance to conventional proteasome inhibitors?
}

Karthik Selvaraju, Magdalena Mazurkiewicz, Xin Wang, Joachim Gullbo, Stig Linder and Padraig D’arcy

\section{Linköping University Post Print}

\section{Tweet}

N.B.: When citing this work, cite the original article.

Original Publication:

Karthik Selvaraju, Magdalena Mazurkiewicz, Xin Wang, Joachim Gullbo, Stig Linder and Padraig D'arcy, Inhibition of proteasome deubiquitinase activity: a strategy to overcome resistance to conventional proteasome inhibitors?, 2015, Drug resistance updates, (21-22), 2029.

http://dx.doi.org/10.1016/j.drup.2015.06.001

Copyright: Elsevier

http://www.elsevier.com/

Postprint available at: Linköping University Electronic Press

http://urn.kb.se/resolve?urn=urn:nbn:se:liu:diva-122221 


\section{Inhibition of proteasome deubiquitinase activity: a strategy to overcome resistance to conventional proteasome inhibitors?}

Karthik Selvaraju ${ }^{\mathrm{a},}$, Magdalena Mazurkiewicz ${ }^{\mathrm{b}}$, Xin Wang $^{\mathrm{a}}$, Joachim Gullbo ${ }^{\mathrm{c}}$, Stig Linder $^{\mathrm{a}, \mathrm{b}}$, and Pádraig D'Arcy ${ }^{\mathrm{a}^{*}}$

${ }^{a}$ Department of Medical and Health Sciences, Linköping University, Linköping, SE-581 85, Sweden.

${ }^{b}$ Department of Oncology and Pathology, Karolinska Institute, SE-171 76, Stockholm, Sweden.

${ }^{c}$ Department of Immunology, Genetics and Pathology, Uppsala University, Uppsala, SE-751 85, Sweden.

* Corresponding author. Tel +4610 1036362

E-mail address: Padraig.Darcy@liu.se 


\begin{abstract}
The ubiquitin-proteasome system (UPS) is the primary mechanism controlling the degradation of damaged, unwanted or short-lived proteins in eukaryotic cells. In addition to protein homeostasis, the UPS has also emerged as a critical node in the regulation of signalling pathways implicated in the growth and survival of cancer cells. The absolute dependency of cancer cells on a functioning UPS has been exploited in the development of anti-cancer therapies as exemplified by development of proteasome inhibitors for the treatment of certain leukemic malignancies. Deubiquitinases (DUBs) are enzyme components of the UPS that catalyse re-editing of poly ubiquitin chains and/or removal of ubiquitin en bloc from target substrates leading to alterations in protein stability and/or downstream signalling. There is a growing recognition that targeting DUB activity may be a feasible option for the development of novel anti-cancer therapies. In particular inhibition of proteasomal cysteine DUBs (i.e. USP14 and UCHL5) has been shown to be particularly cytotoxic to cancer cells leading to the accumulation of ubiquitinated proteins and proteotoxic stress. In this review we focus on the mechanisms of action of proteasome DUB inhibitors as well as the potential of such compounds to circumvent acquired drug resistance in cancer patients.
\end{abstract}

Keywords: cancer therapeutics, small molecule inhibitors, proteasome, deubiquitinase, DUB, $\alpha, \beta$-unsaturated ketones, apoptosis. 


\section{Introduction}

\subsection{The ubiquitin-proteasome system}

Cellular protein degradation is a highly controlled event that ensures that only proteins that are damaged, mis-folded or temporally regulated are removed and destroyed. The ubiquitin proteasome system (UPS) is the main non-lysosomal pathway for protein degradation. At its most basic level, the UPS consists of a selectivity tagging factor in the form of the small molecule ubiquitin, and a multi-subunit proteolytic complex, the proteasome, that functions as the cells' molecular shredder by breaking down unwanted proteins into smaller peptides for subsequent use in cellular metabolism or for presentation in complex with MHC class I to the immune system (Goldberg, 2007; Hershko and Ciechanover, 1998) (Fig. 1). Ubiquitin is a 76 amino acid protein that is highly conserved between all eukaryotes. As part of its function as a destruction tag, it is covalently attached via an isopeptide bond between the carboxy glycine residue of ubiquitin and the $\varepsilon$-amino groups of lysine residues present in proteins destined for degradation. The presence of highly specific ubiquitin receptors on the proteasome ensures that only those proteins displaying the ubiquitin destruction tag are allowed to enter the proteolytic chamber. This degree of selectivity provided by ubiquitin ensures that degradation is a highly controlled event and prevents the unintended proteolysis of cellular proteins. The UPS controls the stability of a diverse range of cellular proteins. Certain substrates such as mis-folded or damaged proteins are targeted to the UPS as a part of a cellular quality control mechanism whose main function is to prevent proteotoxicity by rapidly eliminating the build-up of potentially harmful or toxic proteins. Other UPS regulated proteins are those whose regulation and function is inherently linked to their expression and stability, e.g. cell cycle mediators, oncogene and 
tumour suppressor proteins (Coux et al., 1996; Hershko and Ciechanover, 1998).

The molecular shredder of the UPS is the 26S proteasome, a large multi-subunit protease complex of at least 50 subunits found in the cytosol and the nucleus of eukaryotic cells (Bochtler et al., 1999; Goldberg, 2003; Tanaka et al., 1983). The 26S proteasome can be further subdivided into two functionally distinct complexes: the cylindrical $20 \mathrm{~S}$ core particle (CP) that contains the active sites necessary for proteolysis and the 19S regulatory particle(s) (19S RP) that functions as a selective gatekeeper and facilitator of trafficking into the $20 \mathrm{~S} \mathrm{CP}$. The $20 \mathrm{~S} \mathrm{CP}$ consists of two stacked heptameric inner $\beta$-rings capped by two heptameric $\alpha$-subunits giving the complex a barrel-like cylinder structure (Groll et al., 1997; Unno et al., 2002). The proteolytic activity of the $20 \mathrm{~S} \mathrm{CP}$ is mediated by the $\beta 1, \beta 2$ and $\beta 5$ subunits, associated with caspase-like, trypsin-like and chymotrypsin-like activity respectively, based on the proteolytic preference of the individual $\beta$ subunits for amino acid sequences in target proteins. The hydrolysis of proteins by these subunits generally results in the generation of small peptides of about 3 - 15 amino-acid residues that are expelled from the proteasome for further use in subsequent cellular processes (Groll et al., 1997; Lowe et al., 1995; Puhler et al., 1992; Zwickl et al., 1992). Control of protein translocation to the 20S CP is mediated by the 19S RP, a large complex that caps one or both ends of the 20S CP. The 19S CP contains at least 19 different subunits that are further sub-divided into the lid and base complexes (Glickman et al., 1998; Lander et al., 2012). The base of the 19S RP consists of ten subunits, six of which are related $\mathrm{AAA}^{+}$ATPases, in direct contact with the $\alpha$ subunits of the 20S CP (Tomko et al., 2010). The ATPase activity of the 19S RP is an absolute requirement in facilitating substrate unwinding and opening of the translocation gate of the 20S CP. The other four base subunits are the scaffolding 
proteins Rpn1 and Rpn2 (Bohn et al., 2010), which link the 19S RP to the 20S CP and the ubiquitin receptors S5a/Rpn10 and Rpn13, which recognize and tether ubiquitinated proteins to the proteasome for subsequent processing and degradation (Deveraux et al., 1994; Husnjak et al., 2008).

The attachment of multiple ubiquitin units to proteins provides the functional signal that induces trafficking to the proteasome. However not all ubiquitin signals are equal, the nature of the linkages between ubiquitin molecules on any particular protein ultimately determines the outcome. A ubiquitin code exists whereby proteins tagged with poly-ubiquitin linked via internal K48 or K33 lysine residues are targeted to the proteasome (Kulathu and Komander, 2012). Other linkage types such as K63 are generally involved in non-proteolytic roles such as the regulation of DNA repair and endocytosis pathways. In addition to the nature of lysine linkage types between ubiquitin in a poly-ubiquitin chain, the number of ubiquitin moieties is also an important factor. At least four ubiquitin moieties are the minimum requirement to signal trafficking to the proteasome for degradation. This appears to be a spatial requirement since 4 ubiquitin molecules is the minimum number needed to span the distance between the Rpn10/Rpn13 ubiquitin receptors and the deubiquitinase (DUB) Rpn11/POH1, which plays a key role in the coupling of ubiquitin chain removal to proteasome degradation (see below) (Lander et al., 2012; Piotrowski et al., 1997; Verma et al., 2002; Yao and Cohen, 2002).

The ubiquitination of protein substrates is regulated by an apex cascade of three enzymes, Ubactivating (E1), Ub-conjugating (E2) and Ub-ligating (E3) enzymes that catalyse the activation and conjugation of ubiquitin to target proteins (Hershko et al., 1983). Specificity is conferred by 
the E3 ligases that bind target substrates and co-ordinate the covalent attachment of ubiquitin to lysine residues in the polypeptide chain (Fig. 1). There are $>500$ identified E3 ligases in cells, making these enzymes the main specificity factor in the UPS (Hershko et al., 1983; Pickart and Eddins, 2004; Voges et al., 1999). The process is of ubiquitination is not a one-way street however; the reverse reaction, that is the removal of ubiquitin also occurs in a highly regulated manner. Specialized enzymes, known as deubiquitinases (DUBs), cleave the isopeptide bond between lysine residues on target proteins and the C-terminal glycine residue of ubiquitin thus effectively reversing the activity of the E3 ligases. The human genome encodes $\sim 80$ functional DUBs (Komander et al., 2009), broadly classified into to six groups based on sequence homologies in the catalytic domain: ubiquitin-specific proteases (USPs), ubiquitin carboxyterminal hydrolases (UCHs), ovarian-tumour proteases (OTUs), Machado-Joseph disease protein domain proteases (MJD), JAMM/MPN domain-associated metallopeptidases (JAMMs) and monocyte chemotactic protein-induced protein (MCPIP) (Amerik and Hochstrasser, 2004; Fortelny et al., 2014; Fraile et al., 2012; Nijman et al., 2005). The biological roles of many of these DUBs is a rapidly expanding area of current research; however one thing that is apparent from recent reports is that many of these DUBs appear to play roles in the genesis, maintenance and treatment response of multiple cancer types. As such there is a growing recognition of the therapeutic potential of targeting DUBs as a viable anti-cancer targets. Considering the vast number of DUBs identified we will focus the remainder of the review on proteasome associated DUBs, their potential as drug targets as well as their use as novel therapies to overcome acquired drug resistance. 


\subsection{The role of proteasome associated deubiquitinases (DUBs)}

In order to facilitate degradation, specialized DUBs located within the 19S RP function by removing the bulky polyubiquitin chains on target proteins following their arrival and docking at the proteasome (Verma et al., 2002; Yao and Cohen, 2002). Failure to remove the bulky ubiquitin chains may otherwise sterically hinder the translocation of substrates into the 20S for proteolytic degradation. Other roles include a ubiquitin editing and rescue function, preventing degradation of improperly or insufficiently tagged substrates, a 'toll booth" analogous regulation of ATPase and gate activity and the recycling of ubiquitin chains for further use within the UPS (Finley, 2009; Peth et al., 2009; Peth et al., 2013). In mammalian cells three distinct DUBs are associated with the proteasome: Rpn11/POH1, Ubp6/USP14 and Uch37/UCHL5 (yeast/human nomenclature). POH1 is a metalloprotease belonging to the JAMM domain family and is an integral part of the 19S RP lid (Verma et al., 2002; Yao and Cohen, 2002). POH1 is essential for the viability of both yeast and metazoan cells, with siRNA depletion resulting in the destabilization of the 19S RP lid complex (Gallery et al., 2007; Rinaldi et al., 1998). POH1 contains a JAMM/MPN ${ }^{+}$motif sequence where an aspartic acid and two histidine residues coordinate a zinc ion that is essential for DUB activity (Ambroggio et al., 2004; MaytalKivity et al., 2002). The activity of POH1 is thought to be tightly controlled and only becomes activated once the proteasome is committed to substrate degradation (Lee et al., 2011b; Verma et al., 2002; Yao and Cohen, 2002). POH1 cleaves the proximal end of the poly-ubiquitin chain from the substrate resulting in the release of a free ubiquitin chain and further translocation of the newly de-ubiquitinated substrate to the 20S CP for degradation (Yao and Cohen, 2002). Two other DUBs, UCHL5 and USP14 are cysteine proteases that are also physically associated with 
the base complex of the 19S RP. Interestingly their intrinsic DUB activity is only stimulated upon incorporation into the proteasome, with unbound enzymes displaying significantly reduced levels of DUB activity (Leggett et al., 2002; Yao et al., 2006). Analysis of the structure of USP14 and UCHL5 has revealed the basis of their proteasome dependent activation. In USP14 the ubiquitin binding pocket is obscured by two loops that must be restructured in order to allow access to the active site and activation of deubiquitination activity (Hu et al., 2005). The binding of USP14 to the base of the 19S RP is believed to induce conformational changes in the two loops making the active site more accessible for ubiquitin ( $\mathrm{Hu}$ et al., 2005), and resulting in $\sim 1000$ fold increase in intrinsic DUB activity (Borodovsky et al., 2001). In the case of UCHL5, the UCH-domain contains a crossover loop that precludes the active site and prevents substrate access. Interaction of UCHL5 with the ubiquitin receptor Rpn13/Admr1 reverses this autoinhibitory function leading to restoration of UCHL5 DUB activity (Hamazaki et al., 2006; Qiu et al., 2006; Yao et al., 2006).

In contrast to POH1, USP14 and UCHL5 share a different mode of action and preferentially cleave ubiquitin from the distal ends of ubiquitin chains leading to progressive chain shortening the recycling of ubiquitin back into the UPS. USP14 preferentially cleaves Lys48-linked polyubiquitin chains (Hanna et al., 2006; Hu et al., 2005), whereas UCHL5 appears to be more promiscuous, cleaving both Lys48- and Lys63-linkage types (Jacobson et al., 2009). Interestingly USP14 appears to hinder proteasome degradation by actively trimming ubiquitin chains on target proteins resulting in prolonged occupancy at the 19S RP and potentially favouring release back to the cytosol (Hanna et al., 2006; Lee et al., 2010; Lee et al., 2011a). It would also appear that USP14 is functionally redundant in mammalian cells since knock down 
produced no discernable effects on proteasome structure or polyubiquitin levels (Koulich et al., 2008). Consistent with this, the recently developed small molecule USP14 inhibitor IU1 reduces chain trimming and stimulates the proteasomal degradation of several reporter substrates (Lee et al., 2010). Although non-essential for general cell viability, USP14 does appear to be important for cell survival under certain conditions including metabolic stress and neuronal development (Chen et al., 2009; Chernova et al., 2003; Walters et al., 2008). In particular USP14 appears to play a key role in neuronal function. Mice deficient for USP14 display progressive ataxia and die by 6-10 weeks of age (Wilson et al., 2002), possibly due to defective ubiquitin recycling at synapses leading to altered UPS function (Chen et al., 2009).

In a manner similar to USP14, UCHL5 has also been shown to inhibit protein degradation by shortening the chains of inappropriately or poorly modified substrates under certain conditions (Koulich et al., 2008; Lam et al., 1997). Interestingly an orthologue of human UCHL5 has not been found in $S$. cerevisiae whereas the $S$. pombe orthologue Uch2 is nonessential for viability (Li et al., 2000) possibly suggesting a degree of redundancy between UCHL5 and USP14.

\section{Targeting the UPS in cancer}

Cancer cells are particularly sensitive to fluxuations in the UPS. The exact biological mechanism to why cancer, but not normal cells are sensitive to reduced UPS capacity is likely due to higher rates of protein synthesis and thus greater requirement for UPS mediated protein turnover to maintain homeostasis. This along with a susceptibility to apoptosis induced by endoplasmic reticulum (ER) stress and reactive oxygen species (ROS) following decreased proteasome activity likely explains the cytotoxic effects of proteasome inhibitors on cancer cells (Fig. 2). 
Comparisons of the sensitivity of different cancer sub-types towards proteasome inhibitors does appear to support this, since those cancers with high protein turnover rates also tend to be the most sensitive to proteasome inhibition. For example the plasma cell malignancy, multiple myeloma, hyper-synthesizes defunct immunoglobulins and is generally the most sensitive cancer type towards UPS inhibitors. Such cells with high protein turnover rates can be thought of as in a near constant state of proteotoxic stress caused by the tremendous strain on the protein translation machinery and predisposition to accumulate defective proteins. Thus even small changes in UPS activity are sufficient to result in a catastrophic accumulation of mis-folded immunoglobulin triggering the unfolded protein response (UPR), ER stress and apoptosis (Meister et al., 2007). The clinical development of bortezomib as a treatment for multiple myeloma has validated targeting the UPS as a viable strategy for cancer drug development (Richardson and Anderson, 2003). Bortezomib is peptide boronate derivative that primarily inhibits the chymotrypsin-like activity of the $\beta 5$ subunit, and to a lesser extent the caspase-like activity of the $\beta 1$ subunit of the 20S CP by a covalent but slowly reversible mechanism. The remarkable success of bortezomib has generated much interest in identifying the next generation proteasome inhibitors with different mechanisms of action, altered binding properties or activities on different tumour types (Mitsiades et al., 2009). The epoxyketone carfilzomib (PR171) displays a similar mechanism of action to bortezomib by primarily targeting the chymotryptic activity of the 20S CP (Demo et al., 2007). However; a major difference between the two compounds is drug occupancy, with carfilzomib displaying an irreversible covalent binding mechanism to sites in the $\beta 5$ subunits. Since carfilzomib displays differential binding properties compared to bortezomib it has been approved by the FDA for treatment of multiple myeloma patients that have previously received two prior therapies, including bortezomib and 
who subsequently relapsed. Marizomib (NPI-0052), a natural product derived from the fermentation of the marine actinobacterium Salinospora (Chauhan et al., 2005), also inhibits the chymotryptic-like activity of the $20 \mathrm{~S}$ proteasome via a similar mechanism of action to bortezomib and carfilzomib (Herndon et al., 2013; Obaidat et al., 2011; Singh et al., 2010). Marizomib recently received orphan drug status for the treatment of multiple myeloma and is currently undergoing clinical evaluation (Ma and Diao, 2014).

\section{Proteasomal DUBs as Drug Targets for Cancer Therapy}

The development of proteasome inhibitors has also led to interest in identifying alternative targets that function upstream of the proteasome degradation machinery. Based on their diversity DUBs represent a potential wealth of untapped targets for drug development. DUBs involved in regulating p53 stability or the cell-surface expression of oncogenic receptors have already been mooted as tempting targets for therapeutic intervention with several candidate drugs already in various stages of pre-clinical development (Byun et al., 2013; Chauhan et al., 2012). In particular targeting proteasome-associated deubiquitination has the potential for increasing the levels of ubiquitin conjugated proteins triggering proteotoxic stress and apoptosis similar to that observed with inhibitors of proteolytic activity. The metalloprotease POH1 is an obvious target since it is absolutely required for cell viability and is overexpressed in a variety of tumours (Gallery et al., 2007). Although neither USP14 nor UCHL5 appears to be essential for cell survival alone, dual knockdown using RNA interference has been shown to lead to the accumulation of polyubiquitinated substrates and loss of cell viability (Koulich et al., 2008; Tian et al., 2013; Wang et al., 2014). Interestingly several reports have shown that USP14 is consistently overexpressed in solid tumours of lung and ovarian origin and associated with metastases in colorectal carcinoma 
suggesting a potential role in oncogenesis (Shinji et al., 2006; Wang et al., 2015; Wu et al., 2013). Considering that USP14 and UCHL5 belong to different classes of DUBs, dual inhibition of these enzymes by small molecules would a priori be expected to be possible only in the context of broad-spectrum DUB inhibition. Recently however, a number of compounds have been described that preferentially inhibit proteasomal DUB activity compared to other cytosolic DUBs. The chalcone-derivative b-AP15 (NSC687852) inhibits the activity of USP14 and UCHL5 at concentrations of $\sim 10 \mu \mathrm{M}$ in vitro and $\sim 1 \mu \mathrm{M}$ in vivo ((D'Arcy et al., 2011), Wang et $a l$, submitted) (Fig. 3). The comparatively higher potency observed in vivo is associated with rapid uptake and enrichment in cells (Wang et al., 2014). The cytotoxicity of b-AP15 is tightly linked with functional proteasome inhibition, with the accumulation of the proteasome reporter substrate $\mathrm{Ub}^{\mathrm{G} 76 \mathrm{~V}}$-YFP (Menendez-Benito et al., 2005) preceding and correlating with cell death (Brnjic et al., 2013; Wang et al., 2014b). Examination of the cellular stress response to b-AP15 using gene expression profiling and CMAP analysis (Lamb et al., 2006) showed a similar stress response to that observed following treatment with several well characterized proteasome inhibitors (D'Arcy et al., 2011). In particular genes such as those regulating the chaperone response, ER stress and oxidative stress are typically up regulated following treatment with bAP15 or 20S CP proteasome inhibitors. RA-9 is a small molecule structurally related to b-AP15 that also inhibits proteasomal deubiquitinase activity resulting in a similar stress response and cytotoxicity profile (Brnjic et al., 2014; Coughlin et al., 2014). Another pair of structurally related compounds, G5 and F6, initially identified in a screen for agents that induce apoptosis Bcl-2 over-expressing cells; were subsequently shown to be potent inhibitors of general DUB activity leading to acute proteotoxic stress and apoptosis (Aleo et al., 2006). Finally the 4arylidene curcumin analog $\mathrm{AC} 17$ has been demonstrated to irreversibly inhibit the deubiquitinase 
activity of the 19S RP leading to cell death in in vitro and in vivo models of lung cancer (Zhou et al., 2013). Although these compounds are chemically diverse, a shared similarity is the presence of $\alpha, \beta$-unsaturated ketones and accessible $\beta$-carbons in their chemical structure (Fig. 3). The DUB inhibitory activity is likely to be derived from the electrophilic nature of these compounds and coupled with the fact that the vast majority of DUBs are cysteine proteases that are sensitive to electrophilic attack. Generally cysteine residues in proteins are nucleophilic and tend to show high levels of variation with regard to their reactivity to electrophiles (Codreanu et al., 2014; Weerapana et al., 2010). $\alpha, \beta$-unsaturated ketones are generally considered as relatively soft electrophiles and are speculated to display selective reactivity towards a specific subset of cysteine thiolates in proteins (Aldini et al., 2006). The relative specificity of the various DUB inhibitors described above could potentially be due to the relatively strong reactivity of the cysteine residues located in the active sites of a limited number of DUBs. Interestingly the specificities of $\alpha, \beta$-unsaturated ketone-containing compounds towards various DUBs have been reported to vary considerably. For example whereas b-AP15 was reported to be specific to proteasomal deubiquitinases (D'Arcy et al., 2011), the structurally related compound RA-9 was reported to display more broad range activity and shown to inhibit UCHL1, UCHL3, USP2 and USP8 in addition to the proteasomal DUBs (Anchoori et al., 2011; Coughlin et al., 2014; Issaenko and Amerik, 2012). The chalcone-derivative G5 was also reported to display a broad spectrum of inhibition of DUB activity (Aleo et al., 2006; Nicholson et al., 2008). The curcuminanalog $\mathrm{AC} 17$ was found to be a specific irreversible proteasomal DUBs inhibitor producing a cellular phenotype similar to that observed with b-AP15 (D'Arcy et al., 2011; Zhou et al., 2013). The mechanism(s) underlying these variations in target specificity are unclear, however, it does appears that not all cysteine enzymes are general targets of $\alpha, \beta$-unsaturated ketone-containing 
compounds, since neither glutathione reductase nor caspase-3, both of which contain critical cysteine residues in their active sites, are inhibited by b-AP15 (Wang et al., 2014b) (X.W., unpublished information). However it is likely that some of these differences may reflect the differential binding to target DUBs based on the 3-D conformation of the inhibitors. Considering the similar molecular structures of these drugs, it is surprising however that G5/F6 are broad specificity DUB inhibitors, whereas b-AP15 is specific to proteasomal DUBs. Further work will hopefully clarify these issues. Irrespective of the degree of specificity of different compounds to proteasomal DUB activity, it is likely that inhibition of proteasomal DUB (USP14/UCHL5) activity is of key importance in producing the cytotoxic effects observed when cells are exposed to $\alpha, \beta$-unsaturated ketone-containing compounds.

\section{Overcoming bortezomib resistance using deubiquitinase inhibitors}

\subsection{Mechanisms of resistance to bortezomib and other inhibitors of 20 S proteasome activity}

In spite of the clinical success of bortezomib in the treatment multiple myeloma, the majority of patients eventually acquire resistance and relapse (Kale and Moore, 2012; Kumar and Rajkumar, 2008; Niewerth et al., 2015). The molecular mechanisms underlying the development of resistance to bortezomib are becoming increasingly understood (for recent reviews, see (Kale and Moore, 2012; Niewerth et al., 2015)). Mutations in the genes encoding the catalytic $\beta$ subunits appear to be a key mechanism in the development of bortezomib resistance during selection in vitro. Mutation hot spots clustered around the drug binding site of the $\beta 5$ subunit have been described in numerous cell lines (de Wilt et al., 2012; Franke et al., 2011; Lu et al., 2008; Oerlemans et al., 2008; Ri et al., 2010; Suzuki et al., 2011). In spite of the overwhelming 
data obtained from the study of cell lines, the clinical picture is less clear since $\beta 5$ mutations are generally absent from biopsies obtained from patients displaying bortezomib-resistance (Niewerth et al., 2015). In addition to mutation, the overexpression of $\beta 5$ subunits has also been frequently observed in cell lines with acquired bortezomib resistance and is generally paralleled by down-regulation of immunoproteasome subunits (Franke et al., 2011; Niewerth et al., 2014; Oerlemans et al., 2008).

The altered activity of ABC-drug efflux pumps has also been implicated in conferring bortezomib resistance. Stable knockdown of MDR-1 (encoding the P-glycoprotein, P-gp) in cell lines was observed to lead to a 5-fold increase in sensitivity to bortezomib (Rumpold et al., 2007). However, a number of studies have subsequently shown that bortezomib is generally a poor substrate for P-gp, thus the overall significance of drug efflux pumps in conferring bortezomib resistance is unknown (Minderman et al., 2007; Verbrugge et al., 2012; Wiberg et al., 2009). In contrast to bortezomib, epoxyketone proteasome inhibitors such as ONX 0912 do appear to be P-gp substrates (Verbrugge et al., 2012).

Another potential molecular mechanism of bortezomib resistance is the overexpression of members of the Bcl-2 family of anti-apoptotic mediators such as the $\mathrm{Bcl}-2$ and $\mathrm{Bcl}-\mathrm{X}_{\mathrm{L}}$ proteins (Hagenbuchner et al., 2010; Smith et al., 2011). Both Bcl-2 and Bcl- $\mathrm{X}_{\mathrm{L}}$ function to dampen the apoptotic response by hindering Bax-Bak mediated perforation of the mitochondrial outer membrane, thus preventing cytochrome-c release and activation of the caspase cascade. Several groups have reported that the anti-tumour effect of bortezomib is greatly enhanced by antagonists of Bcl-2 function (Johnson-Farley et al., 2015; Kunami et al., 2014; Paoluzzi et al., 2008; Reuland et al., 2012). The Bcl-2 inhibitors ABT-737 and ABT-199 respectively enhance 
the cytotoxicity of bortezomib in adult T-cell leukaemia/lymphoma (Kunami et al., 2014) and "double hit" lymphoma cells (Johnson-Farley et al., 2015). The BH3 mimetic AT-101, a paninhibitor of Bcl-2, Bcl- $\mathrm{X}_{\mathrm{L}}$ and Mcl-1was also reported to enhance apoptosis when combined with carfilzomib, but not with bortezomib in mantle cell lymphoma (Paoluzzi et al., 2008). This difference in synergy observed is presumably due to the irreversible binding of carfilzomib to the proteasome compared to the slowly reversible nature of bortezomib.

\subsection{Proteasome DUB inhibitors may be used to treat cells with acquired resistance to bortezomib}

Considering the various mechanisms by which cancer cells develop resistance to proteasome inhibitors, targeting alternative components of the UPS may be a logical therapeutic strategy. Mutations or alterations in the expression of $20 \mathrm{~S} \beta$-subunits would not be expected to affect the sensitivity to drugs that target the UPS at the level proteasomal DUBs since these enzymes function upstream of the proteolytic activity of the $20 \mathrm{~S} \mathrm{CP}$. Interestingly the wiring of cell death signalling appears to differ between inhibitors of proteasomal degradation and inhibitors of proteasome DUB activity suggesting a degree of independence in death signalling. For example, apoptosis induced by the proteasome DUB inhibitor b-AP15 is refractory to the overexpression of the anti-apoptotic Bcl-2 protein (D'Arcy et al., 2011) and the expression levels of the proapoptotic Bax and Bak proteins. In contrast Bcl-2 overexpression or loss of Bax and Bak was sufficient to perturb bortezomib-induced apoptosis (Brnjic et al., 2014; D'Arcy et al., 2011). Consistent with these differences in mechanism of action and apoptosis signalling it has been shown that that bortezomib-resistant multiple myeloma cells retain sensitivity to b-AP15 
suggesting a potential treatment to over-come bortezomib resistance (Tian et al., 2013). A bAP15 analogue with improved biological activity (VLX1570; Wang et al., under revision) has recently been approved by the United States Food and Drug Administration for clinical trials and will hopefully aid in the treatment of bortezomib-resistant multiple myeloma.

\subsection{Potential mechanisms of resistance to proteasome DUB inhibitors}

Considering that the development of drug-resistance tends to be a universal problem in the fight against cancer, is it possible to predict what mechanism that may confer resistance to proteasome DUB inhibitors? Mutation of the catalytic cysteines of USP14/UCHL5 could be expected to lead to the loss of b-AP15 binding capacity, however such mutations have to our knowledge not been described and may not be compatible will cell viability. In order to examine potential drug resistance mechanisms, we have attempted to generate b-AP15-resistant cell lines by culturing cells in the presence of b-AP15 for extended periods. However, in spite of 9 months of continuous drug selection, only a small degree of resistance ( $\sim 2$-fold) was achieved, suggesting that the development of acquired resistance is a slow process (Sun et al., unpublished data).

One mechanism that could theoretically be speculated to contribute to b-AP15 resistance is the increased activity of cellular detoxification systems, in particular glutathionylation processes that have the potential to react with and soak up free drug from the intracellular environment. However since glutathione has a $\mathrm{pK}_{\mathrm{a}}$ of $\sim 9.4$ (Tajc et al., 2004) and is present in its thiol-form (i.e. not thiolate-form) at neutral $\mathrm{pH}$ it will only show weak spontaneous reaction with soft electrophiles such as b-AP15. Consistent with this we have found that addition of $2 \mathrm{mM}$ 
glutathione does not significantly inhibit the ability of b-AP15 to inhibit proteasomal DUB activity (D'Arcy et al., 2011). Cross-conjugated dienones are known to undergo reversible Michael addition reactions with glutathione, generating an equilibrium shift to the free form of the electrophile (Suzuki et al., 1997). However since the levels of glutathione in the NCI-60 cell line panel have been determined (Tew et al., 1996) it is possible to investigate the relationship between cellular $\mathrm{IC}_{50}$ values to b-AP15 and cytosolic glutathione levels. No correlation between the sensitivity of the NCI -60 cell lines to b-AP15 and glutathione levels was observed (Fig. 4). Since glutathione is enzymatically conjugated to electrophiles by the action of glutathione-Stransferases (GSTs) such as GST- $\pi$, over expression of such enzymes could be predicted to have a detoxifying role. b-AP15 qualifies as a GST substrate since these are generally hydrophobic and have carbon at the electrophilic centres (Townsend and Tew, 2003). However similar to the expression of glutathione, the expression of GST- $\pi$ in the NCI-60 cell line panel (Tew et al., 1996) showed no correlation to the anti-proliferative activity of b-AP15 (Fig. 4). Another mechanism that could confer resistance to b-AP15 is the increased activity or expression of ABC-drug pumps. However even this appears to be unlikely since available data suggests that bAP15 is not a substrate for either MDR1 or MRP drug pumps as overexpression of the corresponding cDNAs in cancer cell lines does not significantly increase drug resistance (Paola Perego, Fondazione IRCCS, Istituto Nazionale dei Tumori, personal communication). Taken together both the theoretical considerations and experimental findings seem to suggest that development of drug resistance to proteasome DUB inhibitors may be difficult. 


\section{Perspectives}

The proteasome is the only target in the UPS for which a drug has been developed and subsequently approved for clinical use. The clinical success of bortezomib and other secondgeneration proteasome inhibitors has raised the possibility of targeting alternative upstream components of the UPS. Since proteasomal DUB activity is a pre-requisite for proper proteasome function these DUBs represent attractive targets for the development of novel UPS inhibitors. The differences in the molecular mechanism of action of $20 \mathrm{~S}$ proteasome inhibitors and proteasome DUB inhibitors make the development of drug cross-resistance unlikely. Based on the available data proteasome DUB inhibition may be provide a novel mechanism in overcoming drug resistance to conventional proteasome inhibitors and may add to the arsenal of drugs available for the treatment of cancer.

\section{Acknowledgements}

This study was supported by research funding from Cancerfonden, Vetenskapsrådet, Radiumhemmets forskningsfonder, Barncancerfonden, Alex and Eva Wallströms Foundation and Åke Olssons Foundation.

\section{Conflicts of interest}

Two of the authors (P.D and S.L.) are shareholders in Vivolux AB, a company that develops DUB inhibitors to be used as cancer therapeutics. 


\section{References}

Aldini, G., Dalle-Donne, I., Colombo, R., Maffei Facino, R., Milzani, A. and Carini, M., 2006.

Lipoxidation-derived reactive carbonyl species as potential drug targets in preventing protein carbonylation and related cellular dysfunction. ChemMedChem 1, 1045-1058.

Aleo, E., Henderson, C.J., Fontanini, A., Solazzo, B. and Brancolini, C., 2006. Identification of new compounds that trigger apoptosome-independent caspase activation and apoptosis. Cancer research $66,9235-9244$.

Ambroggio, X.I., Rees, D.C. and Deshaies, R.J., 2004. JAMM: a metalloprotease-like zinc site in the proteasome and signalosome. PLoS biology 2, E2.

Amerik, A.Y. and Hochstrasser, M., 2004. Mechanism and function of deubiquitinating enzymes. Biochimica et biophysica acta 1695, 189-207.

Anchoori, R.K., Khan, S.R., Sueblinvong, T., Felthauser, A., Iizuka, Y., Gavioli, R., Destro, F., Isaksson Vogel, R., Peng, S., Roden, R.B. and Bazzaro, M., 2011. Stressing the ubiquitin-proteasome system without 20S proteolytic inhibition selectively kills cervical cancer cells. PloS one 6, e23888.

Bochtler, M., Ditzel, L., Groll, M., Hartmann, C. and Huber, R., 1999. The proteasome. Annual review of biophysics and biomolecular structure 28, 295-317.

Bohn, S., Beck, F., Sakata, E., Walzthoeni, T., Beck, M., Aebersold, R., Forster, F., Baumeister, W. and Nickell, S., 2010. Structure of the 26S proteasome from Schizosaccharomyces pombe at subnanometer resolution. Proceedings of the National Academy of Sciences of the United States of America 107, 20992-20997.

Borodovsky, A., Kessler, B.M., Casagrande, R., Overkleeft, H.S., Wilkinson, K.D. and Ploegh, H.L., 2001. A novel active site-directed probe specific for deubiquitylating enzymes reveals proteasome association of USP14. The EMBO journal 20, 5187-5196.

Brnjic, S., Mazurkiewicz, M., Fryknas, M., Sun, C., Zhang, X., Larsson, R., D'Arcy, P. and Linder, S., 2014. Induction of tumor cell apoptosis by a proteasome deubiquitinase inhibitor is associated with oxidative stress. Antioxidants \& redox signaling 21, 2271-2285.

Byun, S., Lee, S.Y., Lee, J., Jeong, C.H., Farrand, L., Lim, S., Reddy, K., Kim, J.Y., Lee, M.H., Lee, H.J., Bode, A.M., Won Lee, K. and Dong, Z., 2013. USP8 is a novel target for overcoming gefitinib resistance in lung cancer. Clinical cancer research 19, 3894-3904.

Chauhan, D., Catley, L., Li, G., Podar, K., Hideshima, T., Velankar, M., Mitsiades, C., Mitsiades, N., Yasui, H., Letai, A., Ovaa, H., Berkers, C., Nicholson, B., Chao, T.H., Neuteboom, S.T., Richardson, P., Palladino, M.A. and Anderson, K.C., 2005. A novel orally active proteasome inhibitor induces 
apoptosis in multiple myeloma cells with mechanisms distinct from Bortezomib. Cancer cell 8, 407419.

Chauhan, D., Tian, Z., Nicholson, B., Kumar, K.G., Zhou, B., Carrasco, R., McDermott, J.L., Leach, C.A., Fulcinniti, M., Kodrasov, M.P., Weinstock, J., Kingsbury, W.D., Hideshima, T., Shah, P.K., Minvielle, S., Altun, M., Kessler, B.M., Orlowski, R., Richardson, P., Munshi, N. and Anderson, K.C., 2012. A small molecule inhibitor of ubiquitin-specific protease-7 induces apoptosis in multiple myeloma cells and overcomes bortezomib resistance. Cancer cell 22, 345-358.

Chen, P.C., Qin, L.N., Li, X.M., Walters, B.J., Wilson, J.A., Mei, L. and Wilson, S.M., 2009. The proteasome-associated deubiquitinating enzyme Usp14 is essential for the maintenance of synaptic ubiquitin levels and the development of neuromuscular junctions. The Journal of neuroscience 29, 10909-10919.

Chernova, T.A., Allen, K.D., Wesoloski, L.M., Shanks, J.R., Chernoff, Y.O. and Wilkinson, K.D., 2003. Pleiotropic effects of Ubp6 loss on drug sensitivities and yeast prion are due to depletion of the free ubiquitin pool. The Journal of biological chemistry 278, 52102-52115.

Codreanu, S.G., Ullery, J.C., Zhu, J., Tallman, K.A., Beavers, W.N., Porter, N.A., Marnett, L.J., Zhang, B. and Liebler, D.C., 2014. Alkylation damage by lipid electrophiles targets functional protein systems. Molecular \& cellular proteomics 13, 849-859.

Coughlin, K., Anchoori, R., Iizuka, Y., Meints, J., MacNeill, L., Vogel, R.I., Orlowski, R.Z., Lee, M.K., Roden, R.B. and Bazzaro, M., 2014. Small-molecule RA-9 inhibits proteasome-associated DUBs and ovarian cancer in vitro and in vivo via exacerbating unfolded protein responses. Clinical cancer research 20, 3174-3186.

Coux, O., Tanaka, K. and Goldberg, A.L., 1996. Structure and functions of the 20S and 26S proteasomes. Annu Rev Biochem 65, 801-847.

D'Arcy, P., Brnjic, S., Olofsson, M.H., Fryknas, M., Lindsten, K., De Cesare, M., Perego, P., Sadeghi, B., Hassan, M., Larsson, R. and Linder, S., 2011. Inhibition of proteasome deubiquitinating activity as a new cancer therapy. Nat Med 17, 1636-1640.

de Wilt, L.H., Jansen, G., Assaraf, Y.G., van Meerloo, J., Cloos, J., Schimmer, A.D., Chan, E.T., Kirk, C.J., Peters, G.J. and Kruyt, F.A., 2012. Proteasome-based mechanisms of intrinsic and acquired bortezomib resistance in non-small cell lung cancer. Biochemical pharmacology 83, 207-217.

Demo, S.D., Kirk, C.J., Aujay, M.A., Buchholz, T.J., Dajee, M., Ho, M.N., Jiang, J., Laidig, G.J., Lewis, E.R., Parlati, F., Shenk, K.D., Smyth, M.S., Sun, C.M., Vallone, M.K., Woo, T.M., Molineaux, C.J. and Bennett, M.K., 2007. Antitumor activity of PR-171, a novel irreversible inhibitor of the proteasome. Cancer Res 67, 6383-6391. 
Deveraux, Q., Ustrell, V., Pickart, C. and Rechsteiner, M., 1994. A 26 S protease subunit that binds ubiquitin conjugates. The Journal of biological chemistry 269, 7059-7061.

Finley, D., 2009. Recognition and processing of ubiquitin-protein conjugates by the proteasome. Annu Rev Biochem 78, 477-513.

Fortelny, N., Cox, J.H., Kappelhoff, R., Starr, A.E., Lange, P.F., Pavlidis, P. and Overall, C.M., 2014. Network analyses reveal pervasive functional regulation between proteases in the human protease web. PLoS biology 12, e1001869.

Fraile, J.M., Quesada, V., Rodriguez, D., Freije, J.M. and Lopez-Otin, C., 2012. Deubiquitinases in cancer: new functions and therapeutic options. Oncogene 31, 2373-2388.

Franke, N.E., Niewerth, D., Assaraf, Y.G., van Meerloo, J., Vojtekova, K., van Zantwijk, C.H., Zweegman, S., Chan, E.T., Kirk, C.J., Geerke, D.P., Schimmer, A.D., Kaspers, G.J., Jansen, G. and Cloos, J., 2012. Impaired bortezomib binding to mutant beta5 subunit of the proteasome is the underlying basis for bortezomib resistance in leukemia cells. Leukemia 26, 757-768.

Gallery, M., Blank, J.L., Lin, Y., Gutierrez, J.A., Pulido, J.C., Rappoli, D., Badola, S., Rolfe, M. and Macbeth, K.J., 2007. The JAMM motif of human deubiquitinase Poh1 is essential for cell viability. Mol Cancer Ther 6, 262-268.

Glickman, M.H., Rubin, D.M., Coux, O., Wefes, I., Pfeifer, G., Cjeka, Z., Baumeister, W., Fried, V.A. and Finley, D., 1998. A subcomplex of the proteasome regulatory particle required for ubiquitinconjugate degradation and related to the COP9-signalosome and eIF3. Cell 94, 615-623.

Goldberg, A.L., 2007. Functions of the proteasome: from protein degradation and immune surveillance to cancer therapy. Biochemical Society transactions 35, 12-17.

Goldberg, A.L., 2003. Protein degradation and protection against misfolded or damaged proteins. Nature 426, 895-899.

Groll, M., Ditzel, L., Lowe, J., Stock, D., Bochtler, M., Bartunik, H.D. and Huber, R., 1997. Structure of 20S proteasome from yeast at 2.4 A resolution. Nature 386, 463-471.

Hagenbuchner, J., Ausserlechner, M.J., Porto, V., David, R., Meister, B., Bodner, M., Villunger, A., Geiger, K. and Obexer, P., 2010. The anti-apoptotic protein BCL2L1/Bcl-xL is neutralized by pro-apoptotic PMAIP1/Noxa in neuroblastoma, thereby determining bortezomib sensitivity independent of prosurvival MCL1 expression. The Journal of biological chemistry 285, 6904-6912.

Hamazaki, J., Iemura, S., Natsume, T., Yashiroda, H., Tanaka, K. and Murata, S., 2006. A novel proteasome interacting protein recruits the deubiquitinating enzyme UCH37 to $26 \mathrm{~S}$ proteasomes. The EMBO journal 25, 4524-4536. 
Hanna, J., Hathaway, N.A., Tone, Y., Crosas, B., Elsasser, S., Kirkpatrick, D.S., Leggett, D.S., Gygi, S.P., King, R.W. and Finley, D., 2006. Deubiquitinating enzyme Ubp6 functions noncatalytically to delay proteasomal degradation. Cell 127, 99-111.

Herndon, T.M., Deisseroth, A., Kaminskas, E., Kane, R.C., Koti, K.M., Rothmann, M.D., Habtemariam, B., Bullock, J., Bray, J.D., Hawes, J., Palmby, T.R., Jee, J., Adams, W., Mahayni, H., Brown, J., Dorantes, A., Sridhara, R., Farrell, A.T. and Pazdur, R., 2013. U.s. Food and Drug Administration approval: carfilzomib for the treatment of multiple myeloma. Clinical cancer research 19, 45594563.

Hershko, A. and Ciechanover, A., 1998. The ubiquitin system. Annu Rev Biochem 67, 425-479. Hershko, A., Heller, H., Elias, S. and Ciechanover, A., 1983. Components of ubiquitin-protein ligase system. Resolution, affinity purification, and role in protein breakdown. The Journal of biological chemistry 258, 8206-8214.

Hu, M., Li, P., Song, L., Jeffrey, P.D., Chenova, T.A., Wilkinson, K.D., Cohen, R.E. and Shi, Y., 2005. Structure and mechanisms of the proteasome-associated deubiquitinating enzyme USP14. The EMBO journal 24, 3747-3756.

Husnjak, K., Elsasser, S., Zhang, N., Chen, X., Randles, L., Shi, Y., Hofmann, K., Walters, K.J., Finley, D. and Dikic, I., 2008. Proteasome subunit Rpn13 is a novel ubiquitin receptor. Nature 453, 481-488.

Issaenko, O.A. and Amerik, A.Y., 2012. Chalcone-based small-molecule inhibitors attenuate malignant phenotype via targeting deubiquitinating enzymes. Cell cycle 11, 1804-1817.

Jacobson, A.D., Zhang, N.Y., Xu, P., Han, K.J., Noone, S., Peng, J. and Liu, C.W., 2009. The lysine 48 and lysine 63 ubiquitin conjugates are processed differently by the 26 s proteasome. The Journal of biological chemistry 284, 35485-35494.

Johnson-Farley, N., Veliz, J., Bhagavathi, S. and Bertino, J.R., 2015. ABT-199, a BH3 mimetic that specifically targets Bcl-2, enhances the antitumor activity of chemotherapy, bortezomib and JQ1 in "double hit" lymphoma cells. Leukemia \& lymphoma, 1-7.

Kale, A.J. and Moore, B.S., 2012. Molecular mechanisms of acquired proteasome inhibitor resistance. Journal of medicinal chemistry 55, 10317-10327.

Komander, D., Clague, M.J. and Urbe, S., 2009. Breaking the chains: structure and function of the deubiquitinases. Nature Reviews Molecular cell biology 10, 550-563.

Koulich, E., Li, X. and DeMartino, G.N., 2008. Relative structural and functional roles of multiple deubiquitylating proteins associated with mammalian 26S proteasome. Mol Biol Cell 19, 10721082.

Kulathu, Y. and Komander, D., 2012. Atypical ubiquitylation - the unexplored world of polyubiquitin beyond Lys48 and Lys63 linkages. Nature Reviews Molecular cell biology 13, 508-523. 
Kumar, S. and Rajkumar, S.V., 2008. Many facets of bortezomib resistance/susceptibility. Blood 112, 21772178.

Kunami, N., Katsuya, H., Nogami, R., Ishitsuka, K. and Tamura, K., 2014. Promise of combining a Bcl-2 family inhibitor with bortezomib or SAHA for adult T-cell leukemia/lymphoma. Anticancer research 34, 5287-5294.

Lam, Y.A., Xu, W., DeMartino, G.N. and Cohen, R.E., 1997. Editing of ubiquitin conjugates by an isopeptidase in the $26 \mathrm{~S}$ proteasome. Nature 385, 737-740.

Lamb, J., Crawford, E.D., Peck, D., Modell, J.W., Blat, I.C., Wrobel, M.J., Lerner, J., Brunet, J.P., Subramanian, A., Ross, K.N., Reich, M., Hieronymus, H., Wei, G., Armstrong, S.A., Haggarty, S.J., Clemons, P.A., Wei, R., Carr, S.A., Lander, E.S. and Golub, T.R., 2006. The Connectivity Map: using gene-expression signatures to connect small molecules, genes, and disease. Science 313, $1929-1935$.

Lander, G.C., Estrin, E., Matyskiela, M.E., Bashore, C., Nogales, E. and Martin, A., 2012. Complete subunit architecture of the proteasome regulatory particle. Nature 482, 186-191.

Lee, B.H., Lee, M.J., Park, S., Oh, D.C., Elsasser, S., Chen, P.C., Gartner, C., Dimova, N., Hanna, J., Gygi, S.P., Wilson, S.M., King, R.W. and Finley, D., 2010. Enhancement of proteasome activity by a small-molecule inhibitor of USP14. Nature 467, 179-184.

Lee, M.J., Lee, B.H., Hanna, J., King, R.W. and Finley, D., 2011a. Trimming of ubiquitin chains by proteasome-associated deubiquitinating enzymes. Mol Cell Proteomics 10, R110 003871.

Lee, M.J., Lee, B.H., Hanna, J., King, R.W. and Finley, D., 2011b. Trimming of ubiquitin chains by proteasome-associated deubiquitinating enzymes. Molecular \& cellular proteomics 10(5), R110.003871.

Leggett, D.S., Hanna, J., Borodovsky, A., Crosas, B., Schmidt, M., Baker, R.T., Walz, T., Ploegh, H. and Finley, D., 2002. Multiple associated proteins regulate proteasome structure and function. Mol Cell 10, 495-507.

Li, T., Naqvi, N.I., Yang, H. and Teo, T.S., 2000. Identification of a 26S proteasome-associated UCH in fission yeast. Biochemical and biophysical research communications 272, 270-275.

Lowe, J., Stock, D., Jap, B., Zwickl, P., Baumeister, W. and Huber, R., 1995. Crystal structure of the 20S proteasome from the archaeon T. acidophilum at 3.4 A resolution. Science 268, 533-539.

Lu, S., Yang, J., Song, X., Gong, S., Zhou, H., Guo, L., Song, N., Bao, X., Chen, P. and Wang, J., 2008. Point mutation of the proteasome beta5 subunit gene is an important mechanism of bortezomib resistance in bortezomib-selected variants of Jurkat $\mathrm{T}$ cell lymphoblastic lymphoma/leukemia line. The Journal of pharmacology and experimental therapeutics 326, 423-431. 
Ma, L. and Diao, A., 2014. Marizomib, a potent second generation proteasome inhibitor from natural origin. Anti-cancer agents in medicinal chemistry, EPub Nov 14.

Maytal-Kivity, V., Reis, N., Hofmann, K. and Glickman, M.H., 2002. MPN+, a putative catalytic motif found in a subset of MPN domain proteins from eukaryotes and prokaryotes, is critical for Rpn11 function. BMC Biochem 3, 28.

Meister, S., Schubert, U., Neubert, K., Herrmann, K., Burger, R., Gramatzki, M., Hahn, S., Schreiber, S., Wilhelm, S., Herrmann, M., Jack, H.M. and Voll, R.E., 2007. Extensive immunoglobulin production sensitizes myeloma cells for proteasome inhibition. Cancer research 67, 1783-1792.

Menendez-Benito, V., Verhoef, L.G., Masucci, M.G. and Dantuma, N.P., 2005. Endoplasmic reticulum stress compromises the ubiquitin-proteasome system. Hum Mol Genet 14, 2787-2799.

Minderman, H., Zhou, Y., O'Loughlin, K.L. and Baer, M.R., 2007. Bortezomib activity and in vitro interactions with anthracyclines and cytarabine in acute myeloid leukemia cells are independent of multidrug resistance mechanisms and p53 status. Cancer chemotherapy and pharmacology 60, 245255.

Mitsiades, C.S., Hideshima, T., Chauhan, D., McMillin, D.W., Klippel, S., Laubach, J.P., Munshi, N.C., Anderson, K.C. and Richardson, P.G., 2009. Emerging treatments for multiple myeloma: beyond immunomodulatory drugs and bortezomib. Semin Hematol 46, 166-175.

Nicholson, B., Leach, C.A., Goldenberg, S.J., Francis, D.M., Kodrasov, M.P., Tian, X., Shanks, J., Sterner, D.E., Bernal, A., Mattern, M.R., Wilkinson, K.D. and Butt, T.R., 2008. Characterization of ubiquitin and ubiquitin-like-protein isopeptidase activities. Protein science : a publication of the Protein Society 17, 1035-1043.

Niewerth, D., Jansen, G., Assaraf, Y.G., Zweegman, S., Kaspers, G.J. and Cloos, J., 2015. Molecular basis of resistance to proteasome inhibitors in hematological malignancies. Drug resistance updates : reviews and commentaries in antimicrobial and anticancer chemotherapy 18, 18-35.

Niewerth, D., Kaspers, G.J., Assaraf, Y.G., van Meerloo, J., Kirk, C.J., Anderl, J., Blank, J.L., van de Ven, P.M., Zweegman, S., Jansen, G. and Cloos, J., 2014. Interferon-gamma-induced upregulation of immunoproteasome subunit assembly overcomes bortezomib resistance in human hematological cell lines. Journal of hematology \& oncology 7, 7.

Nijman, S.M., Luna-Vargas, M.P., Velds, A., Brummelkamp, T.R., Dirac, A.M., Sixma, T.K. and Bernards, R., 2005. A genomic and functional inventory of deubiquitinating enzymes. Cell 123, 773-786.

Obaidat, A., Weiss, J., Wahlgren, B., Manam, R.R., Macherla, V.R., McArthur, K., Chao, T.H., Palladino, M.A., Lloyd, G.K., Potts, B.C., Enna, S.J., Neuteboom, S.T. and Hagenbuch, B., 2011. Proteasome regulator marizomib (NPI-0052) exhibits prolonged inhibition, attenuated efflux, and greater 
cytotoxicity than its reversible analogs. The Journal of pharmacology and experimental therapeutics $337,479-486$.

Oerlemans, R., Franke, N.E., Assaraf, Y.G., Cloos, J., van Zantwijk, I., Berkers, C.R., Scheffer, G.L., Debipersad, K., Vojtekova, K., Lemos, C., van der Heijden, J.W., Ylstra, B., Peters, G.J., Kaspers, G.L., Dijkmans, B.A., Scheper, R.J. and Jansen, G., 2008. Molecular basis of bortezomib resistance: proteasome subunit beta5 (PSMB5) gene mutation and overexpression of PSMB5 protein. Blood 112, 2489-2499.

Paoluzzi, L., Gonen, M., Gardner, J.R., Mastrella, J., Yang, D., Holmlund, J., Sorensen, M., Leopold, L., Manova, K., Marcucci, G., Heaney, M.L. and O'Connor, O.A., 2008. Targeting Bcl-2 family members with the BH3 mimetic AT-101 markedly enhances the therapeutic effects of chemotherapeutic agents in in vitro and in vivo models of B-cell lymphoma. Blood 111, 5350-5358.

Peth, A., Besche, H.C. and Goldberg, A.L., 2009. Ubiquitinated proteins activate the proteasome by binding to Usp14/Ubp6, which causes 20S gate opening. Mol Cell 36, 794-804.

Peth, A., Kukushkin, N., Bosse, M. and Goldberg, A.L., 2013. Ubiquitinated proteins activate the proteasomal ATPases by binding to Usp14 or Uch37 homologs. The Journal of biological chemistry 288, 7781-7790.

Pickart, C.M. and Eddins, M.J., 2004. Ubiquitin: structures, functions, mechanisms. Biochimica et biophysica acta $1695,55-72$.

Piotrowski, J., Beal, R., Hoffman, L., Wilkinson, K.D., Cohen, R.E. and Pickart, C.M., 1997. Inhibition of the $26 \mathrm{~S}$ proteasome by polyubiquitin chains synthesized to have defined lengths. The Journal of biological chemistry 272, 23712-23721.

Puhler, G., Weinkauf, S., Bachmann, L., Muller, S., Engel, A., Hegerl, R. and Baumeister, W., 1992. Subunit stoichiometry and three-dimensional arrangement in proteasomes from Thermoplasma acidophilum. The EMBO journal 11, 1607-1616.

Qiu, X.B., Ouyang, S.Y., Li, C.J., Miao, S., Wang, L. and Goldberg, A.L., 2006. hRpn13/ADRM1/GP110 is a novel proteasome subunit that binds the deubiquitinating enzyme, UCH37. The EMBO journal 25, 5742-5753.

Reuland, S.N., Goldstein, N.B., Partyka, K.A., Smith, S., Luo, Y., Fujita, M., Gonzalez, R., Lewis, K., Norris, D.A. and Shellman, Y.G., 2012. ABT-737 synergizes with Bortezomib to kill melanoma cells. Biology open 1, 92-100.

Ri, M., Iida, S., Nakashima, T., Miyazaki, H., Mori, F., Ito, A., Inagaki, A., Kusumoto, S., Ishida, T., Komatsu, H., Shiotsu, Y. and Ueda, R., 2010. Bortezomib-resistant myeloma cell lines: a role for mutated PSMB5 in preventing the accumulation of unfolded proteins and fatal ER stress. Leukemia 24, 1506-1512. 
Richardson, P.G. and Anderson, K.C., 2003. Bortezomib: a novel therapy approved for multiple myeloma. Clin Adv Hematol Oncol 1, 596-600.

Rinaldi, T., Ricci, C., Porro, D., Bolotin-Fukuhara, M. and Frontali, L., 1998. A mutation in a novel yeast proteasomal gene, RPN11/MPR1, produces a cell cycle arrest, overreplication of nuclear and mitochondrial DNA, and an altered mitochondrial morphology. Mol Biol Cell 9, 2917-2931.

Rumpold, H., Salvador, C., Wolf, A.M., Tilg, H., Gastl, G. and Wolf, D., 2007. Knockdown of PgP resensitizes leukemic cells to proteasome inhibitors. Biochemical and biophysical research communications 361, 549-554.

Shinji, S., Naito, Z., Ishiwata, S., Ishiwata, T., Tanaka, N., Furukawa, K., Suzuki, H., Seya, T., Matsuda, A., Katsuta, M. and Tajiri, T., 2006. Ubiquitin-specific protease 14 expression in colorectal cancer is associated with liver and lymph node metastases. Oncology reports 15, 539-543.

Singh, A.V., Palladino, M.A., Lloyd, G.K., Potts, B.C., Chauhan, D. and Anderson, K.C., 2010. Pharmacodynamic and efficacy studies of the novel proteasome inhibitor NPI-0052 (marizomib) in a human plasmacytoma xenograft murine model. British journal of haematology 149, 550-559.

Smith, A.J., Dai, H., Correia, C., Takahashi, R., Lee, S.H., Schmitz, I. and Kaufmann, S.H., 2011. Noxa/Bcl-2 protein interactions contribute to bortezomib resistance in human lymphoid cells. The Journal of biological chemistry 286, 17682-17692.

Suzuki, E., Demo, S., Deu, E., Keats, J., Arastu-Kapur, S., Bergsagel, P.L., Bennett, M.K. and Kirk, C.J., 2011. Molecular mechanisms of bortezomib resistant adenocarcinoma cells. PloS one 6, e27996.

Tajc, S.G., Tolbert, B.S., Basavappa, R. and Miller, B.L., 2004. Direct determination of thiol pKa by isothermal titration microcalorimetry. Journal of the American Chemical Society 126, 1050810509.

Tanaka, K., Waxman, L. and Goldberg, A.L., 1983. ATP serves two distinct roles in protein degradation in reticulocytes, one requiring and one independent of ubiquitin. The Journal of cell biology 96, 15801585.

Tew, K.D., Monks, A., Barone, L., Rosser, D., Akerman, G., Montali, J.A., Wheatley, J.B. and Schmidt, D.E., Jr., 1996. Glutathione-associated enzymes in the human cell lines of the National Cancer Institute Drug Screening Program. Molecular pharmacology 50, 149-159.

Tian, Z., D'Arcy, P., Wang, X., Ray, A., Tai, Y.T., Hu, Y., Carrasco, R.D., Richardson, P., Linder, S., Chauhan, D. and Anderson, K.C., 2013. A novel small molecule inhibitor of deubiquitylating enzyme USP14 and UCHL5 induces apoptosis in multiple myeloma and overcomes bortezomib resistance. Blood 125, 706-716. 
Tomko, R.J., Jr., Funakoshi, M., Schneider, K., Wang, J. and Hochstrasser, M., 2010. Heterohexameric ring arrangement of the eukaryotic proteasomal ATPases: implications for proteasome structure and assembly. Mol Cell 38, 393-403.

Townsend, D.M. and Tew, K.D., 2003. The role of glutathione-S-transferase in anti-cancer drug resistance. Oncogene 22, 7369-7375.

Unno, M., Mizushima, T., Morimoto, Y., Tomisugi, Y., Tanaka, K., Yasuoka, N. and Tsukihara, T., 2002. The structure of the mammalian $20 \mathrm{~S}$ proteasome at 2.75 A resolution. Structure (London, England : 1993) 10, 609-618.

Verbrugge, S.E., Assaraf, Y.G., Dijkmans, B.A., Scheffer, G.L., Al, M., den Uyl, D., Oerlemans, R., Chan, E.T., Kirk, C.J., Peters, G.J., van der Heijden, J.W., de Gruijl, T.D., Scheper, R.J. and Jansen, G., 2012. Inactivating PSMB5 mutations and P-glycoprotein (MDR1/ ABCB1) mediate resistance to proteasome inhibitors: ex vivo efficacy of (immuno) proteasome inhibitors in mononuclear blood cells from rheumatoid arthritis patients. The Journal of pharmacology and experimental therapeutics,

Verma, R., Aravind, L., Oania, R., McDonald, W.H., Yates, J.R., 3rd, Koonin, E.V. and Deshaies, R.J., 2002. Role of Rpn11 metalloprotease in deubiquitination and degradation by the $26 \mathrm{~S}$ proteasome. Science 298, 611-615.

Voges, D., Zwickl, P. and Baumeister, W., 1999. The 26S proteasome: a molecular machine designed for controlled proteolysis. Annu Rev Biochem 68, 1015-1068.

Walters, B.J., Campbell, S.L., Chen, P.C., Taylor, A.P., Schroeder, D.G., Dobrunz, L.E., ArtavanisTsakonas, K., Ploegh, H.L., Wilson, J.A., Cox, G.A. and Wilson, S.M., 2008. Differential effects of Usp14 and Uch-L1 on the ubiquitin proteasome system and synaptic activity. Molecular and cellular neurosciences 39, 539-548.

Wang, X., Stafford, W., Mazurkiewicz, M., Fryknas, M., Brjnic, S., Zhang, X., Gullbo, J., Larsson, R., Arner, E.S., D'Arcy, P. and Linder, S., 2014. The 19S Deubiquitinase inhibitor b-AP15 is enriched in cells and elicits rapid commitment to cell death. Molecular pharmacology 85, 932-945.

Wang, Y., Wang, J., Zhong, J., Deng, Y., Xi, Q., He, S., Yang, S., Jiang, L., Huang, M., Tang, C. and Liu, R., 2015. Ubiquitin-specific protease 14 (USP14) regulates cellular proliferation and apoptosis in epithelial ovarian cancer. Medical oncology 32, 379.

Weerapana, E., Wang, C., Simon, G.M., Richter, F., Khare, S., Dillon, M.B., Bachovchin, D.A., Mowen, K., Baker, D. and Cravatt, B.F., 2010. Quantitative reactivity profiling predicts functional cysteines in proteomes. Nature 468, 790-795. 
Wiberg, K., Carlson, K., Aleskog, A., Larsson, R., Nygren, P. and Lindhagen, E., 2009. In vitro activity of bortezomib in cultures of patient tumour cells--potential utility in haematological malignancies. Medical oncology 26, 193-201.

Wilson, S.M., Bhattacharyya, B., Rachel, R.A., Coppola, V., Tessarollo, L., Householder, D.B., Fletcher, C.F., Miller, R.J., Copeland, N.G. and Jenkins, N.A., 2002. Synaptic defects in ataxia mice result from a mutation in Usp14, encoding a ubiquitin-specific protease. Nat Genet 32, 420-425.

Wu, N., Liu, C., Bai, C., Han, Y.P., Cho, W.C. and Li, Q., 2013. Over-Expression of deubiquitinating enzyme USP14 in lung adenocarcinoma promotes proliferation through the accumulation of betacatenin. International journal of molecular sciences 14, 10749-10760.

Yao, T. and Cohen, R.E., 2002. A cryptic protease couples deubiquitination and degradation by the proteasome. Nature 419, 403-407.

Yao, T., Song, L., Xu, W., DeMartino, G.N., Florens, L., Swanson, S.K., Washburn, M.P., Conaway, R.C., Conaway, J.W. and Cohen, R.E., 2006. Proteasome recruitment and activation of the Uch37 deubiquitinating enzyme by Adrm1. Nature cell biology 8, 994-1002.

Zhou, B., Zuo, Y., Li, B., Wang, H., Liu, H., Wang, X., Qiu, X., Hu, Y., Wen, S., Du, J. and Bu, X., 2013. Deubiquitinase inhibition of 19S regulatory particles by 4-arylidene curcumin analog AC17 causes NF-kappaB inhibition and p53 reactivation in human lung cancer cells. Mol Cancer Ther 12, 13811392.

Zwickl, P., Grziwa, A., Puhler, G., Dahlmann, B., Lottspeich, F. and Baumeister, W., 1992. Primary structure of the Thermoplasma proteasome and its implications for the structure, function, and evolution of the multicatalytic proteinase. Biochemistry 31, 964-972. 


\section{Figure 1}

\section{Ubiquitin Proteasome System (UPS)}

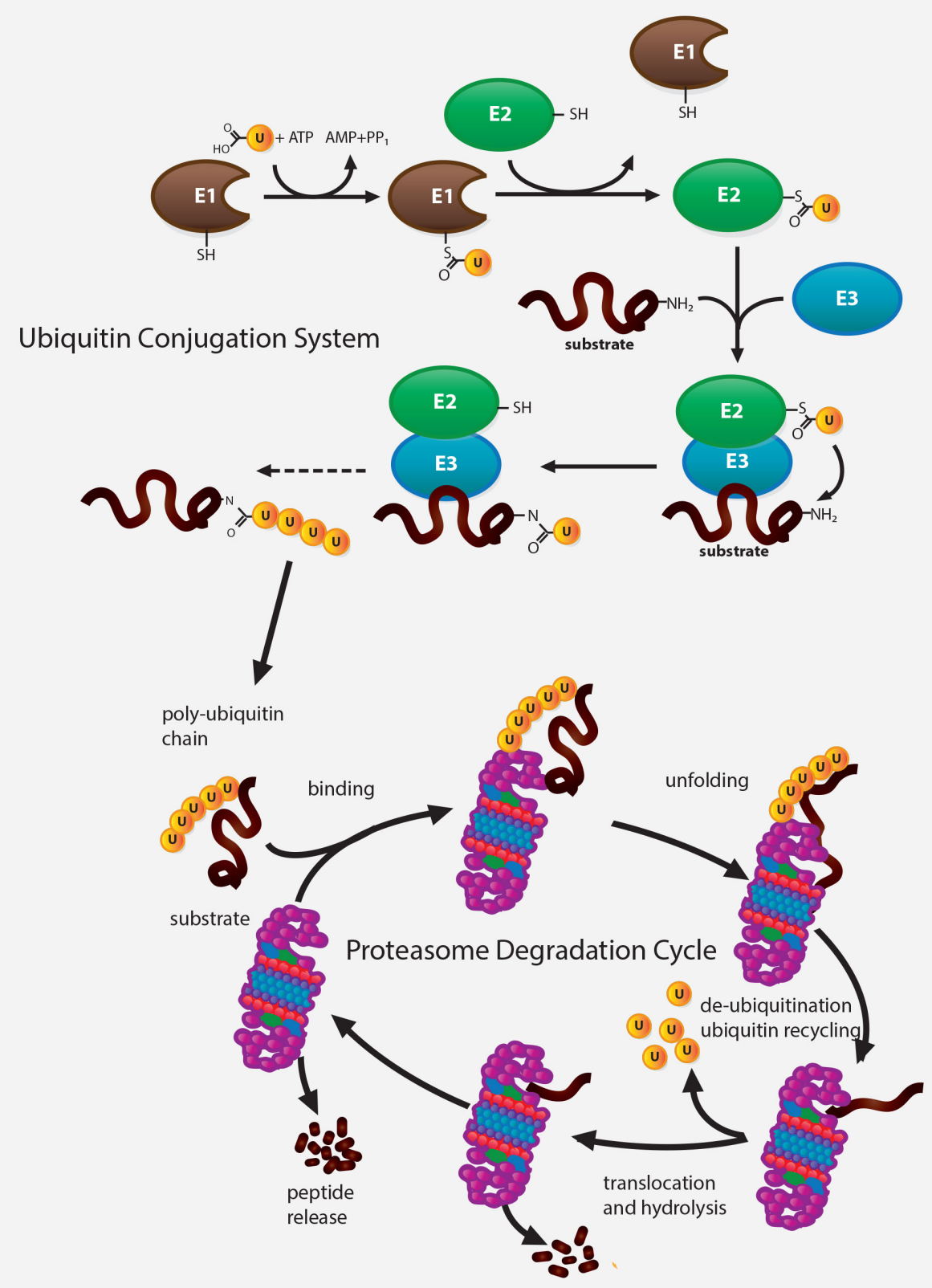

Figure 1. Controlled protein degradation is mediated by the ubiquitin-proteasome system (UPS). Cascades of ligases work sequentially to covalently modify lysine residues on target proteins with the small molecule ubiquitin. The attachment of multiple ubiquitin residues signals trafficking to the proteasome and recognition by the ubiquitin receptors located at the 19S RP. Substrates are partially unfolded and stripped of their polyubiquitin chains by proteasomeassociated DUBs prior to translocation into the $20 \mathrm{~S}$ particle for proteolysis. 


\section{Figure 2}

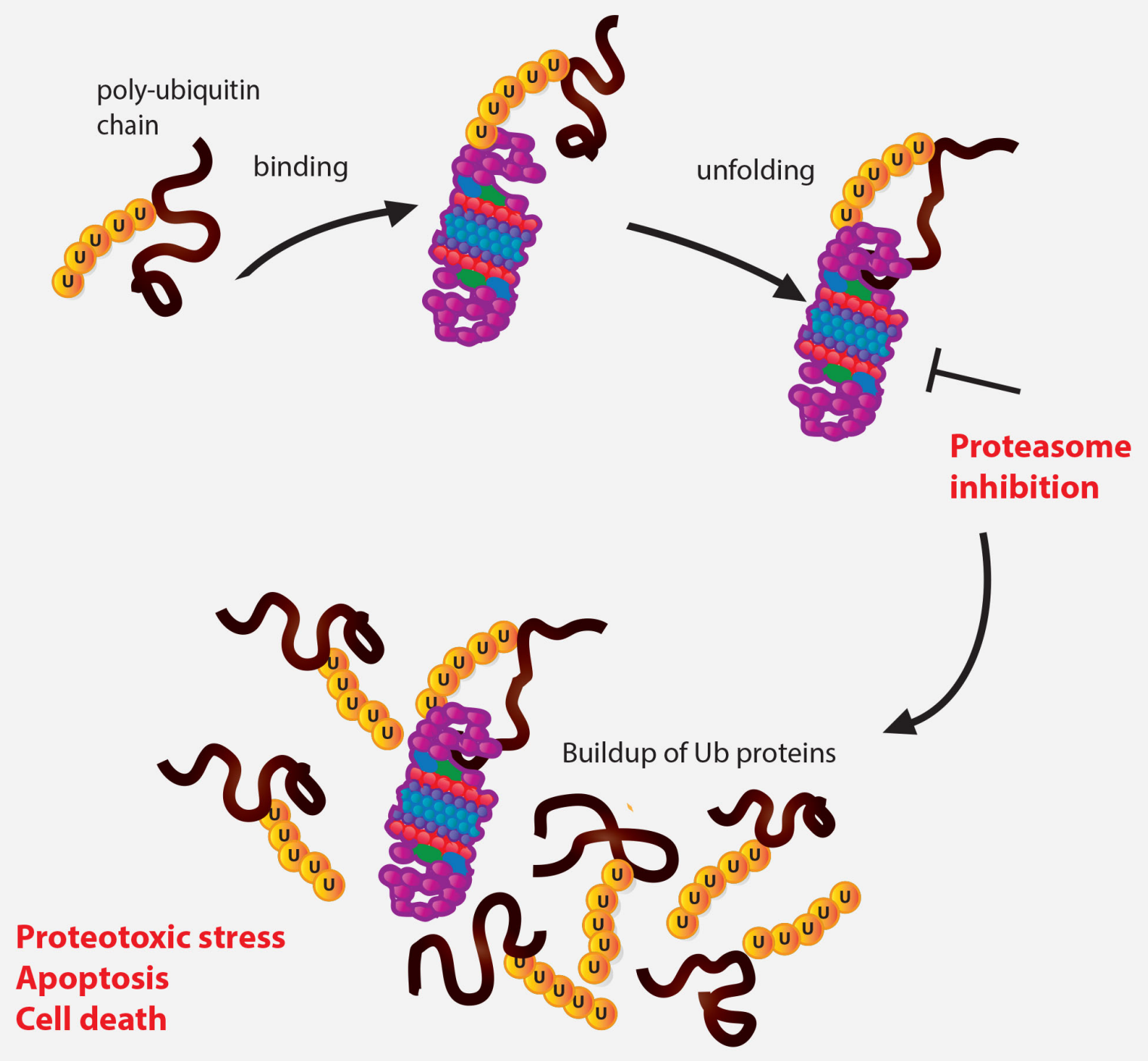

Figure 2. Mechanism of proteasome inhibitor induced cytotoxicity.

Inhibition of UPS activity can lead to a build up of cytotoxic proteins that accumulate within the cell. The build-up of polyubiquitinated proteins can induce a proteotoxic stress response characterized by endoplasmic reticulum (ER) stress, production of reactive oxygen species (ROS), activation of apoptosis and cell death. 


\section{Figure 3}

\section{b-AP15}<smiles>C=CC(=O)N1C/C(=C\c2ccc([N+](=O)[O-])cc2)C(=O)/C(=C/c2ccc([N+](=O)[O-])cc2)C1</smiles>

F6<smiles>Cc1ccc(/C=C2\CNC/C(=C\c3ccc(C)cc3)C2=O)cc1</smiles>

\section{RA-9}<smiles>O=C1/C(=C/c2ccc([N+](=O)[O-])cc2)CNC/C1=C\c1ccc([N+](=O)[O-])cc1</smiles>

G5<smiles>O=C1/C(=C/c2ccc([N+](=O)[O-])cc2)CS(=O)(=O)C/C1=C\c1ccc([N+](=O)[O-])cc1</smiles>

\section{AC17}

Figure 3. Chemical structure of proteasome DUB inhibitors sharing $\alpha, \beta$-unsaturated ketones and accessible $\beta$-carbons. Several characterized proteasome DUB inhibitors share a similar chemical structure consisting of sterically accessible $\beta$-carbons and $\alpha, \beta$-unsaturated ketones. Such a pharmacophore is presumed to react with the cysteine residues in the active sites of DUBs. 
Figure 4
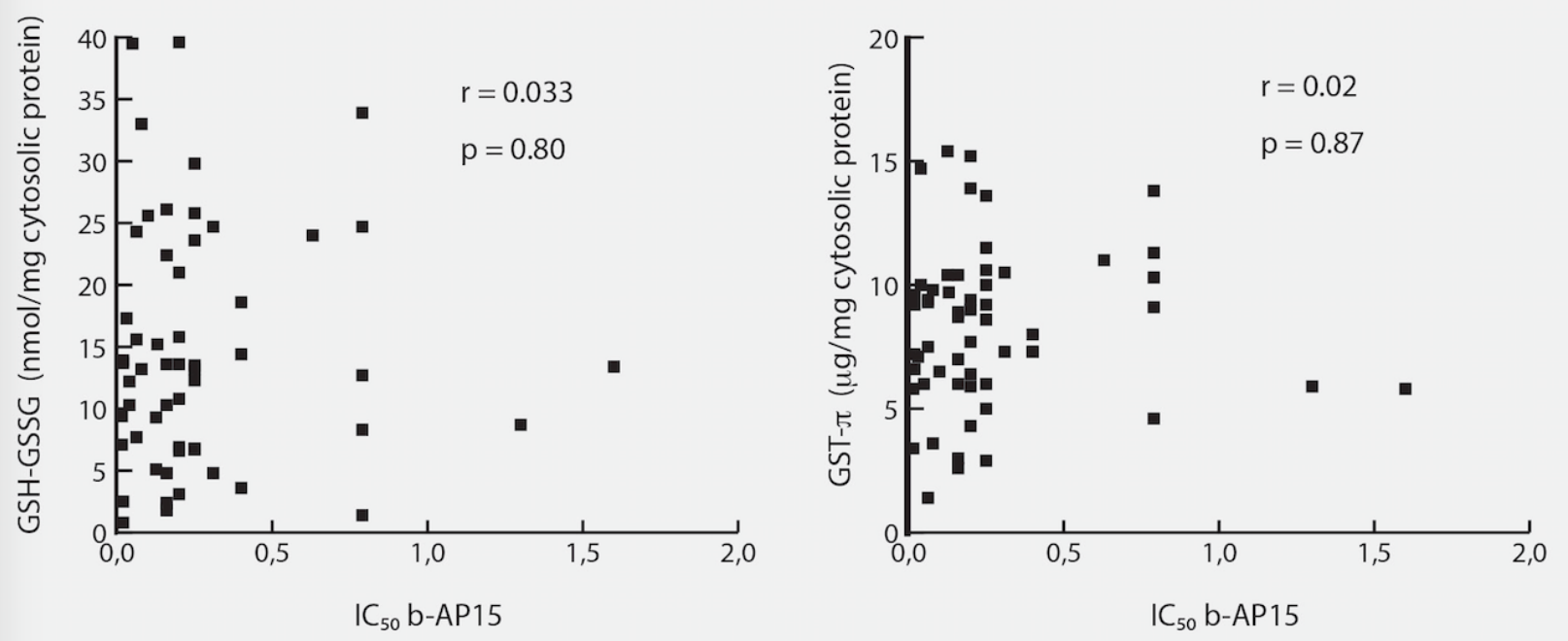

Figure 4. GSH and GST- $\pi$ levels do not correlate to b-AP15 sensitivity. Glutathione (GSH) and Glutathione S Transferase- $\pi$ (GST- $\pi$ ) are components of the cells detoxification system that could potentially lead to b-AP15 resistance. Analysis of the expression levels of GSH and GST- $\pi$ in the NCI60 cell line panel shows no correlation with expression levels and b-AP15 sensitivity. 